\title{
Infrequent cross-transmission of Shigella flexneri 2a strains among villages of a mountainous township in Taiwan with endemic shigellosis
}

Ching-Fen Ko ${ }^{1,2}$, Nien-Tsung Lin ${ }^{1,3}$, Chien-Shun Chiou' ${ }^{4}$, Li-Yu Wang ${ }^{5}$, Ming-Ching Liu ${ }^{6}$, Chiou-Ying Yang ${ }^{7}$ and Yeong-Sheng Lee , $^{8 *}$

\begin{abstract}
Background: Shigellosis is rare in Taiwan, with an average annual incidence rate of 1.68 cases per 100,000 persons in 2000-2007. However, the incidence rate for a mountainous township in eastern Taiwan, Zhuoxi, is 60.2 times the average rate for the entire country. Traveling between Zhuoxi's 6 villages (V1-V6) is inconvenient. Disease transmission among the villages/tribes with endemic shigellosis was investigated in this study.

Methods: Demographic data were collected in 2000-2010 for epidemiological investigation. Thirty-eight Shigella flexneri 2a isolates were subjected to pulsed-field gel electrophoresis (PFGE) genotyping and antimicrobial susceptibility testing (AST).

Results: Fifty-five shigellosis cases were identified in 2000-2007, of which 38 were caused by S. flexneri 2a from 2000-2007, 16 cases were caused by S. sonnei from 2000-2003, and 1 case was caused by S. flexneri 3b in 2006. S. flexneri 2 a caused infections in 4 of the 6 villages of Zhuoxi Township, showing the highest prevalence in villages V2 and V5. PFGE genotyping categorized the 38 S. flexneri 2a isolates into 2 distinct clusters (clones), 1 and 2. AST results indicated that most isolates in cluster 1 were resistant to ampicillin, chloramphenicol, streptomycin, sulfamethoxazole and trimethoprim-sulfamethoxazole (ACSSUX); all isolates in cluster 2 were resistant to ACSSUX and tetracycline. Genotypes were primarily unique to different villages or tribes. Tribe V2-1 showed the highest endemic rates. Eighteen isolates recovered from V2-1 tribe members fell into 6 genotypes, where 5 were the same clone (cluster 1). An outbreak (OB2) in 2004 in village V2 was caused by different clonal strains; cases in tribe V2-1 were caused by 2 strains of clone 1, and those in tribe V2-2 were infected by a strain of clone 2 .
\end{abstract}

Conclusions: From 2000-2007, 2 S. flexneri 2a clones circulated among 4 villages/tribes in the eastern mountainous township of Zhuoxi. Genotyping data showed restricted disease transmission between the villages and tribes, which may be associated with difficulties in traveling between villages and limited contact between different ethnic aborigines. Transmission of shigellosis in this township likely occurred via person-to-person contact. The endemic disease was controlled by successful public health intervention.

Keywords: Shigella, Molecular epidemiology, Disease transmission/control, Pulsed-field gel electrophoresis (PFGE), Antibiotic resistance

\footnotetext{
* Correspondence: cdc0948th@mail.tcu.edu.tw

${ }^{8}$ Department of Public Health, Tzu Chi University, No. 701, Zhongyang Rd., Sec. 3,

Hualien 97004, Taiwan

${ }^{9}$ The Fourth Branch Office, Centers for Disease Control, No. 752, Sec. 2,

Datong Rd., Tainan 70256, Taiwan

Full list of author information is available at the end of the article
} 


\section{Background}

Shigellosis, caused by Shigella species such as Shigella dysenteriae, S. flexneri, S. boydii, and S. sonnei, is one of the most frequent causes of diarrhea in children. Approximately 164.7 million cases are documented per year worldwide resulting in 1.1 million deaths, and two-thirds of the patients are children under 5 years of age [1]. However, these figures may be significantly underestimated [2-4]. The disease is highly contagious, with infectious doses of as low as 10-100 viable Shigella cells and an incubation period of 1-5 days. Large outbreaks of this disease typically occur in overcrowded areas with poor sanitary conditions or due to food or water that is contaminated by the pathogen [5-14]. Shigellosis transmission occurs primarily through person-to-person contact, most commonly among young children in households and populated institutes [15-17]. Community outbreaks have been frequently associated with daycare centers and school attendees $[18,19]$. Epidemic and endemic cases are most frequently caused by $S$. dysenteriae and S. flexneri in developing countries and S. sonnei in developed countries [1,20-23]. In the United States, $72.3 \%$ of infections are caused by S. sonnei and $14.3 \%$ are caused by $S$. flexneri, primarily affecting children under 9 years of age (54.1\%) [21].

Shigellosis is a notifiable disease in Taiwan. In 20002007, 139-1,355 cases of shigellosis were identified each year, with an average incidence rate of 1.68 cases per 100,000 persons [24]. Most cases were identified in mountainous townships inhabited by aboriginal Taiwanese people, who accounts for $2 \%$ of the population in Taiwan. The incidence rate of shigellosis among aboriginal townships is $21-120$ times of that in populated urban areas of Taiwan [25]. Notably, most cases observed in mountainous townships were caused by S. flexneri, whereas those in populated urban areas were caused by $S$. sonnei $[5,6,26,27]$. S. flexneri 2 a was the most commonly identified agent causing endemic shigellosis among the aboriginal townships in Taiwan [5,6].

From 2000-2007, 55 shigellosis cases were identified in the villages of the mountainous township of Zhuoxi in eastern Taiwan. The township includes different ethnic aborigines living in villages/tribes. In the present study, we characterized 38 S. flexneri 2a isolates using pulsed-field gel electrophoresis (PFGE) analysis and antimicrobial susceptibility testing (AST) to investigate the mode of transmission of shigellosis among villages and tribes over a period of 8 years.

\section{Methods}

\section{Epidemiological investigation}

Shigellosis is one of the notifiable diseases in Taiwan; demographic information of patients and contacts are obligatory to report to Taiwan Centers for Disease
Control (Taiwan CDC) by county health authorities. The epidemiological investigation of disease outbreaks was conducted by the Sixth Branch Office of Taiwan CDC and the Hualien County Health Bureau. For each shigellosis case, the patient was interviewed with a routine questionnaire to trace the possible source of infection. Information collected by the questionnaire included personal demographic information, date of onset, symptoms, travel history, source of drinking water and food, ethnicity, family and school contacts, etc. Stool specimens from contacts of patients were subjected to bacterial examination. This study was exempted from the IRB approval for using the delinked data in the Notifiable Disease Database of Taiwan CDC and not uncovering the ethnicity of the subjects.

\section{Bacterial isolates}

From 2000-2010, stool samples of suspected shigellosis patients and their contacts in the Zhuoxi Township were taken as part of standard patient care and forwarded to the Taiwan CDC for bacteriological examination, including Bacillus cereus, Escherichia coli, Salmonella enterica, Shigella spp., Staphylococcus aureus, Vibrio cholerae, and V. parahaemolyticus. Isolates were tested by using Gram-staining, conventional biochemical tests (API 20 E test kit; bioMérieux, Marcy l'Étoile, France), and serotyping by using the slide agglutination method with commercial polyclonal antiserum (Denka Seiken, Tokyo, Japan). Escherichia coli ATCC 25922 and Salmonella enterica serovar Braenderup strain H9812 were used as reference strains for AST and PFGE analyses, respectively.

\section{PFGE and pattern analysis}

Isolates were subjected to PFGE analysis using the standardized PulseNet PFGE protocol for Shigella and other enterobacteria [28], except NotI was used rather than $X b a I$. PFGE images were digitally recorded in tiff file format using a Kodak EDAS290 System (Eastman Kodak Co, Rochester, NY, USA). PFGE fingerprints were analyzed using BioNumerics software version 4.6 (Applied Maths; Kortrijk, Belgium). Isolates differing in 1 or more bands were considered to have different genotypes [29]. A dendrogram for the PFGE patterns was constructed using the Dice similarity coefficient and Unweighted Pair Group Method with Arithmetic Mean (UPGMA) algorithm, with settings for pattern optimization of $1.0 \%$ and band tolerance of $1.0 \%$. In this study, isolates with PFGE pattern similarities of $\geq 80 \%$ were categorized in the same cluster.

\section{Antimicrobial susceptibility testing}

Thirty-three isolates were subjected to antimicrobial susceptibility testing with 12 antimicrobials by using the 
microbroth dilution method with custom-designed 96-well Sensititre MIC panels (TREK Diagnostic Systems LTD., West Essex, England) following the instructions of the manufacturer. Interpretation of the MIC results followed the guidelines of the Clinical and Laboratory Standards Institute (CLSI) [30]. Twelve antimicrobial agents were tested, including ampicillin (AMP), cefotaxime (CTX), ceftazidime (CFZ), chloramphenicol (CHL), ciprofloxacin (CIP), gentamicin (GEN), imipenem (IMI), nalidixic acid (NAL), streptomycin (STR), sulfamethoxazole (SMX), tetracycline (TET), and trimethoprim-sulfamethoxazole (SXT).

\section{Results}

\section{Shigellosis in Zhuoxi Township}

The Zhuoxi Township includes 6 villages (V1 to V6) in which 6,800 aboriginal people live. While these villages are separated by mountains, each village has a country road connected directly to Provincial Highway (Figure 1). Only trails are available for transportation between villages. V2 includes 2 tribes, V2-1 and V2-2, which contain different ethnic aborigines.
From 2000-2007, 55 shigellosis cases (an average incidence rate of 101.1 cases per 100,000 persons) were identified in 5 of the 6 villages, of which 38 cases were caused by S. flexneri 2a in 4 villages in 2000-2007, 16 cases were caused by $S$. sonnei in 3 villages in 2000-2002, and 1 case was caused by S. flexneri 3b in 2006 (Table 1). No shigellosis case was reported during March 2, 2007December 31, 2010.

Because $S$. flexneri 2a infections occurred widely in 4 villages and persisted for 8 years, isolates were collected for further characterization to investigate the mode of transmission among the villages. A total of $38 \mathrm{~S}$. flexneri $2 \mathrm{a}$ isolates were recovered from 24 sporadic cases, SP1SP24, and 2 outbreaks, OB1 (4 cases) and OB2 (10 cases) (Table 2). The median age of the patients was 7.5 years (range, 1-84), 29 of whom were aged less 13 years, while 4 were aged over 60 years.

Outbreak OB1 occurred in tribe V2-1 in 2003, whereas outbreak OB2 occurred in tribesV2-1 and V2-2 in 2004. During the OB2 outbreak, rectal swabs were acquired from 186 suspected patients and their contacts. Ten S. flexneri 2a were identified, which infected children

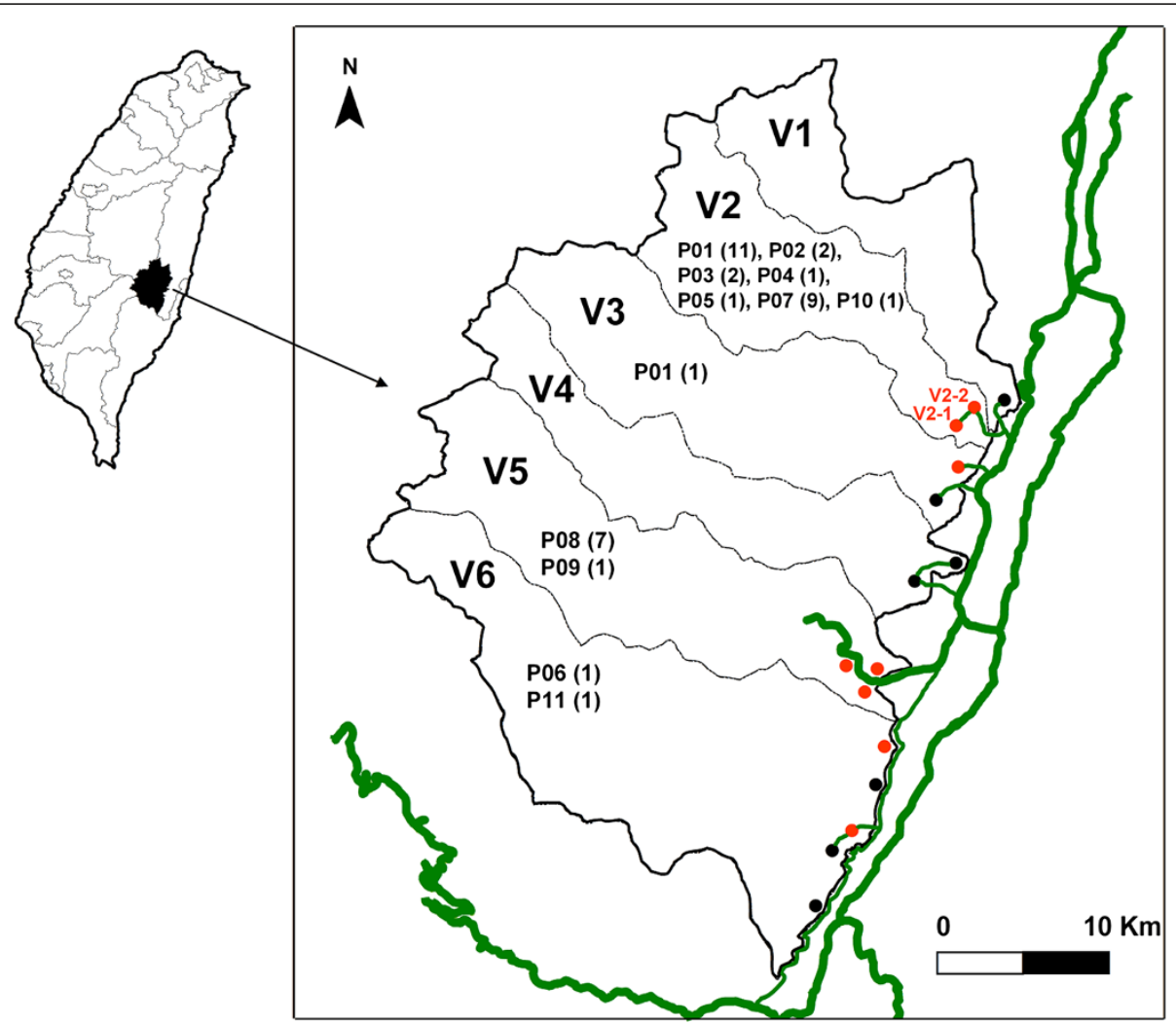

Figure 1 Zhouxi Township map, showing the villages, tribes, genotypes, numbers of shigellosis cases, and road systems. The thicker green lines represent the Provincial Highway system, while the thin green line represents a road connecting the villages and tribes. Tribes with shigellosis during 2000-2007 are indicated in red, and otherwise indicated in black. The genotypes for the isolates and cases in each village are indicated and numbered in parenthesis. 
Table 1 Distribution of shigellosis cases and incidence rates in the villages/tribes of Zhouxi Township, 2000-2007

\begin{tabular}{|c|c|c|c|c|c|c|c|c|}
\hline & V1 & V2-1 & V2-2 & V3 & V5 & V6 & Total & $\begin{array}{c}\text { Incidence } \\
\text { rate }(/ 100000)\end{array}$ \\
\hline 2000 & & 2 & $5(5)$ & & & & $7(5)$ & 98.7 \\
\hline 2001 & $2(2)$ & $3(1)$ & $1(1)$ & 1 & $6(6)$ & & $13(10)$ & 184.1 \\
\hline 2002 & & $3(1)$ & & & & 1 & $4(1)$ & 57.7 \\
\hline 2003 & & 4 & & & & & 4 & 58.8 \\
\hline 2004 & & 4 & 9 & & 4 & & 17 & 253.4 \\
\hline 2005 & & 2 & & & 3 & 1 & 6 & 89.9 \\
\hline 2006 & & & & 1 (1) & 1 & & $2(1)$ & 30.2 \\
\hline 2007 & & $2^{b}$ & & & & & 2 & 30.7 \\
\hline Total & $2(2)$ & $20(2)$ & $15(6)$ & $2(1)$ & $14(6)$ & 2 & 55 (17) & 101.1 \\
\hline
\end{tabular}

${ }^{\mathrm{a}}$ Thirty eight cases were caused by Shigella flexneri 2a; number in parenthesis indicates the number of cases caused by S. sonnei but the case in village V3 in 2006 was caused by S. flexneri 3b. ${ }^{\text {b}}$ The onset date of the last shigellosis case was March 1, 2007; no shigellosis case was reported from March 2,2007 to December $31,2010$.

with a median age of 7.0 years. Ten children were from 2 tribes; 3 were from tribe V2-1 and 7 were from tribe V2-2. Patients were found to be living in the same village, were classmates, or were playmates.

\section{Antimicrobial resistance}

Thirty-three S. flexneri $2 \mathrm{a}$ isolates were subjected to AST. Two resistance patterns were observed; 17 isolates were resistant to ACSSuX (AMP, CHL, STR, SMX, and SXT) and 16 were resistant to ACSSuTX (AMP, CHL, STR, SMX, TET, and SXT) (Table 2).

\section{PFGE analysis}

All 38 S. flexneri 2a isolates recovered in 2000-2007 were subjected to PFGE analysis with NotI. PFGE results were used to categorize these isolates into 11 PFGE types, P01-P11. P01, P07, and P08 were most prevalent. Twelve isolates of the P01 type were responsible for 4 cases of OB1 outbreak and 2 cases of the OB2 outbreak, as well as 5 sporadic cases in tribe V2-1 and 1 case in V3 (Table 2). Nine P07 isolates were recovered from OB2 outbreak cases and 2 sporadic cases in the V2-2 tribe in 2004. Seven P08 isolates were recovered from cases in V5, which had occurred in 2004-2006. Clustering analysis of the 11 PFGE patterns revealed 2 distinct clusters, 1 and 2 (Figure 2). Strains of cluster 1 emerged in villages V2, V3, and V6, whereas strains of cluster 2 emerged in villages V2, V5, and V6. Among the 33 isolates subjected to AST, all but 2 isolates from cluster 1 displayed the ACSSuX resistance pattern, whereas all isolates from cluster 2 were resistant to ACSSuTX (Table 2). The 2 isolates showing ACSSuTX resistance in cluster 1 were of the P02 type, which displayed high pattern similarity with the P01 type. Tribe V2-1 showed endemic issues; 18 shigellosis cases caused by $S$. flexneri 2a occurred over a period of 8 years. The 18 isolates fell into 6 genotypes classes, of which 5 belonged to cluster
1. The isolates recovered from the outbreaks OB2 in tribe V2-1 and tribe V2-2 belonged to different genetic clusters (clones). The 8 isolates recovered in V5 fell into 2 genotypes belonging to clone 2 . However, 2 isolates from V6 were different clones.

\section{Discussion}

In Taiwan, S. flexneri and S. sonnei are the most prevalent species [5,14,31]; S. dysenteriae and S. boydii are infrequently observed, and all are found in imported cases in the most recent 2 decades [26]. S. flexneri, the predominant subserotype 2a, circulated for a long period of time in several mountainous townships in which most of the population includes Taiwanese aborigines [5,6]. $S$. sonnei often causes outbreaks in populated institutes, including elementary schools, military camps, jails, and daycare centers in the industrialized western region of Taiwan $[26,27,31]$. S. sonnei is not prevalent in aboriginal tribes and typically circulates among communities for only a short time. Since 2001, a 4-year shigellosis control program had been implemented in mountainous townships in which endemic shigellosis has been identified [25]. Currently, shigellosis is infrequently observed in aboriginal communities; it was not been detected in the Zhuoxi Township from March 2, 2007 to December 31, 2010.

S. flexneri and S. sonnei were the causes of shigellosis in the Zhuoxi Township in 2000-2007. Most infections occurred in V2 and V5. S. sonnei infections in each village lasted for only 1-2 years, whereas $S$. flexneri infections persisted for much longer as it circulated in tribe V2-1 for at least 8 years (Table 1). PFGE analysis of $38 \mathrm{~S}$. flexneri $2 \mathrm{a}$ isolates revealed that nearly all villages or tribes had unique circulating strains (Table 2, Figure 1). Although tribe V2-1 had 6 genotypes, all but 1 belonged to the same clone. Two genotypes (P08 and P09) identified in isolates from V5 differed in only 1 DNA band, 
Table 2 Epidemiological information and characterization of 38 Shigella flexneri 2a from Zhuoxi Township ${ }^{a}, 2000-2007$

\begin{tabular}{|c|c|c|c|c|c|c|c|c|c|c|}
\hline Patient no. & Isolate code & Gender & Age & Onset date $(\mathrm{m} / \mathrm{d} / \mathrm{y})$ & PFGE subtype & Genetic cluster & Antibiogram $^{\text {b }}$ & Village $^{c}$ & Institution $^{d}$ & Source $^{e}$ \\
\hline 1 & E03.1201 & $M$ & 1 & $11 / 17 / 03$ & P01 & 1 & ACsSuX & V2-1 & $\mathrm{N}$ & OB1 \\
\hline 2 & E03.1260 & M & 15 & $11 / 17 / 03$ & P01 & 1 & ACSSUX & V2-1 & $N$ & OB1 \\
\hline 3 & E03.1437 & $\mathrm{F}$ & 12 & $11 / 19 / 03$ & P01 & 1 & ACSSuX & V2-1 & B & OB1 \\
\hline 4 & E03.1440 & $\mathrm{F}$ & 7 & $11 / 27 / 03$ & P01 & 1 & ACSSuX & V2-1 & B & OB1 \\
\hline 5 & E04.0408 & M & 8 & 03/26/04 & P01 & 1 & ACSSUX & V2-1 & B & OB2 \\
\hline 6 & E04.0453 & $\mathrm{F}$ & 3 & 03/29/04 & P01 & 1 & ACSSuX & V2-1 & A2 & OB2 \\
\hline 7 & E04.0441 & $\mathrm{F}$ & 9 & 03/24/04 & P02 & 1 & ACSSUTX & V2-1 & B & OB2 \\
\hline 8 & E04.0297 & M & 4 & $03 / 12 / 04$ & P07 & 2 & ACSSUTX & V2-2 & $\mathrm{A} 1$ & OB2 \\
\hline 9 & E04.0319 & $\mathrm{F}$ & 7 & 03/16/04 & P07 & 2 & ACSSUTX & V2-2 & $\mathrm{A} 1$ & OB2 \\
\hline 10 & E04.0346 & M & 4 & 03/19/04 & P07 & 2 & ACSSUTX & V2-2 & $\mathrm{A} 1$ & OB2 \\
\hline 11 & E04.0363 & M & 7 & 03/19/04 & P07 & 2 & ACSSUTX & V2-2 & B & OB2 \\
\hline 12 & E04.0354 & $\mathrm{F}$ & 10 & 03/23/04 & P07 & 2 & ACSSUTX & V2-2 & B & OB2 \\
\hline 13 & E04.0472 & $F$ & 4 & 03/29/04 & P07 & 2 & ACSSUTX & V2-2 & $\mathrm{A} 1$ & OB2 \\
\hline 14 & E04.0507 & $F$ & 10 & 03/31/04 & P07 & 2 & ACSSUTX & V2-2 & B & OB2 \\
\hline 15 & E00.0859 & $\mathrm{F}$ & 60 & 09/01/00 & P05 & 1 & ACSSuX & V2-1 & & SP1 \\
\hline 16 & E00.0880 & M & 3 & 09/05/00 & P01 & 1 & ACssuX & V2-1 & $N$ & SP2 \\
\hline 17 & E01.4395 & M & 1 & 09/12/01 & P01 & 1 & ACSSuX & V2-1 & $N$ & SP3 \\
\hline 18 & E01.4508 & $\mathrm{F}$ & 41 & 09/17/01 & P10 & 2 & ND & V2-1 & & SP4 \\
\hline 19 & E02.0431 & $F$ & 67 & 02/27/02 & P01 & 1 & ACSSuX & V2-1 & & SP6 \\
\hline 20 & E02.1665 & $F$ & 78 & $10 / 21 / 02$ & P02 & 1 & ACSSUTX & V2-1 & & SP8 \\
\hline 21 & E04.0026 & $\mathrm{F}$ & 58 & $01 / 04 / 04$ & P01 & 1 & ACSSuX & V2-1 & & SP9 \\
\hline 22 & E05.0245 & $F$ & 9 & 02/24/05 & P01 & 1 & ACSSuX & V2-1 & B & SP18 \\
\hline 23 & E05.0343 & M & 12 & 03/02/05 & P04 & 1 & ACSSuX & V2-1 & B & SP19 \\
\hline 24 & E07.0420 & $\mathrm{F}$ & 2 & 02/15/07 & P03 & 1 & ACSSuX & V2-1 & $N$ & SP23 \\
\hline 25 & E07.0426 & M & 9 & 03/01/07 & P03 & 1 & ACSSuX & V2-1 & B & SP24 \\
\hline 26 & E04.1157 & M & 3 & 07/20/04 & P07 & 2 & ACSSUTX & V2-2 & $N$ & SP11 \\
\hline 27 & E04.1187 & $\mathrm{F}$ & 12 & $07 / 26 / 04$ & P07 & 2 & ACSSUTX & V2-2 & B & SP12 \\
\hline 28 & E01.6570 & $\mathrm{F}$ & 5 & 11/10/01 & P01 & 1 & ACSSuX & V3 & $N$ & SP5 \\
\hline 29 & E04.0925 & M & 4 & $05 / 21 / 04$ & P08 & 2 & ND & V5 & $N$ & SP10 \\
\hline 30 & E04.1469 & M & 4 & 09/04/04 & P09 & 2 & ACSSUTX & V5 & $N$ & SP13 \\
\hline 31 & E04.1909 & M & 2 & $12 / 06 / 04$ & P08 & 2 & ND & V5 & $N$ & SP14 \\
\hline 32 & E04.1939 & M & 1 & $12 / 09 / 04$ & P08 & 2 & ND & V5 & $N$ & SP15 \\
\hline 33 & E05.0004 & M & 7 & $01 / 04 / 05$ & P08 & 2 & ACSSUTX & V5 & $N$ & SP16 \\
\hline 34 & E05.0005 & $\mathrm{F}$ & 8 & $01 / 05 / 05$ & P08 & 2 & ACSSUTX & V5 & $N$ & SP17 \\
\hline 35 & E05.1303 & $F$ & 84 & 08/08/05 & P08 & 2 & ACSSUTX & V5 & & SP21 \\
\hline 36 & E06.5052 & M & 56 & 10/21/06 & P08 & 2 & ND & V5 & & SP22 \\
\hline 37 & E02.0464 & M & 80 & $03 / 12 / 02$ & P11 & 2 & ACSSUTX & V6 & & SP7 \\
\hline 38 & E05.0638 & $M$ & 6 & 05/18/05 & P06 & 1 & ACSSuX & V6 & $N$ & SP20 \\
\hline
\end{tabular}

${ }^{\mathrm{a} Z h u o x i}$, consisting of 6 villages (V1-V6), is a mountainous township in Hualien county in eastern Taiwan. ${ }^{\mathrm{b}}$ Antimicrobial resistance patterns: A, ampicillin; $\mathrm{C}$, chloramphenicol; S, streptomycin; Su, sulfamethoxazole; T, tetracycline; $\mathrm{X}$, trimethoprim-sulfamethoxazole. ND, AST was not done. ${ }^{\mathrm{C}} \mathrm{V} 2-1$ and $\mathrm{V} 2-2$ are 2 tribes in village $\mathrm{V} 2 .{ }^{\mathrm{d}}$ Two day care centers were present in the $\mathrm{V} 2$ village $(\mathrm{A} 1, \mathrm{~A} 2)$ as well as 1 elementary school $(B)$. N, children were not studying in $A 1, A 2$, or $B$ schools. ${ }^{\mathrm{e} O B}$, outbreak; SP, sporadic case.

indicating that they were derived from a common ancestor and caused infections in the village for 3 years (from 2004-2006). Of the 11 genotypes, only P01, the most prevalent type in the V2-1 tribe, was detected in an isolate from V3 (Figure 2). These data indicate that crosstransmission of shigellosis occurred infrequently among 


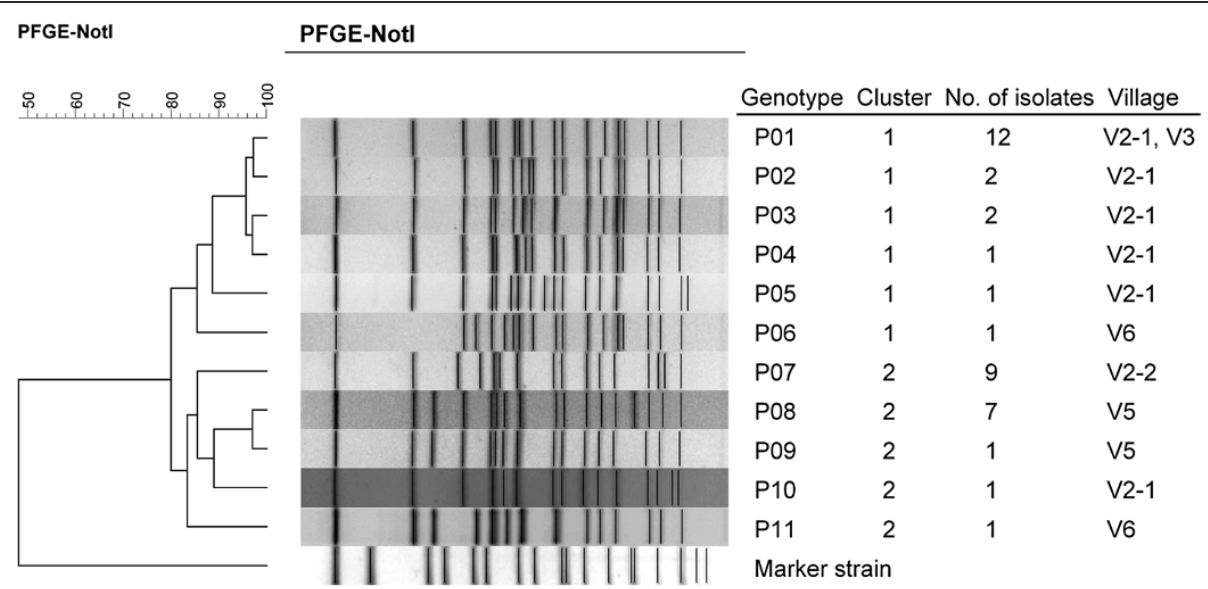

Figure 2 Dendrogram of Shigella flexneri type 2a strains constructed based on Notl-pulsed-field gel electrophoresis patterns.

the villages/tribes of the Zhuoxi Township during 20002007, which was likely due to the inconvenient transport system between villages and different ethnic groups. This reduced interaction and lowered disease transmission between geographic locations.

The OB2 outbreak occurred in tribes V2-1 and V2-2 in March 2004. The 2 tribes are composed of aborigines from different ethnic groups (Figure 1). The 10 infected children attended 2 day care centers and 1 elementary school. Two children from tribe V2-1 and 3 from tribe V2-2 attended the same elementary school (Table 2). Epidemiological investigation suggested a common infection source. However, genotyping data indicated that cases from the tribe V2-1 were infected by 2 strains (P01 and P02) of clone 1 and those from tribe V2-2 were infected by a strain (P07) of clone 2 (Table 2). Thus, OB2 was not a single source outbreak. Genotyping results and epidemiological evidence suggested that infections were likely to occur via person-to-person transmission among family members and playmates in day care center in their respective tribes rather than school where the students came from V2-1 and V2-2. For example, cases $8,9,10$, and 13 were playmates in day care center A1 in tribe V2-2; they were infected by the same strain (genotype P07) with different onset days (Table 2), suggesting that they were transmitted via personal contact.

The $38 S$. flexneri 2a isolates were discriminated by PFGE into 11 genotypes that fell into 2 genetic clusters (clones), suggesting that $S$. flexneri 2 a had been circulating in the Zhuoxi Township for many years. Most isolates of clone 1 displayed ACSSuX resistance and were distributed in tribe V2-1 and villages V3 and V6, circulating from 2000 to 2007. All isolates of clone 2 tested belonged to the ACSSuTX resistance type, which was distributed in tribe V2-2 and the villages V5 and V6, circulating from $2004-2005$, except for 1 case identified in
2002. Although each of the 2 clones was widespread in 3 villages, disease transmission between villages is likely very rare. Briefly, in this study, clones 1 and 2 were associated with antibiogram types ACSSuX and ACSSuTX, respectively, and circulated in different geographical locations inhabited by aborigines from different ethnic groups.

Shigellosis outbreaks in schools can persist for months and can be exacerbated by the poor hygienic practices of young children, making it difficult to control [31]. Since the first case of the OB2 outbreak was reported on March 12, 2004, several intervention measures were implemented in V2 to control the disease. These measures included the following: (1) enforcement of screening of all contacts and school children by stool microbiological examination, (2) enhanced hand-washing practices and environmental disinfection in the schools and community, (3) separation of suspected cases from classrooms, dining tables, and toilets, (4) closing of day care centers for 6 days, (5) confirming shigellosis cases using cultures, (6) chlorination of the community water tower, and (7) implementation of health education of infectious diseases to the community residents. After these efforts, no shigellosis cases were reported from March 2, 2007 to December 31, 2010.

\section{Conclusions}

S. flexneri $2 \mathrm{a}$ was responsible for the endemic infection in the Zhuoxi Township, which is inhabited by aborigines with different ethnic origins. Thirty-eight strains that belonged to 2 clones were identified as causing infections among the villages/tribes in 8 years. Crosstransmission of the pathogen between villages/tribes was rare, which may be due to the poor transport system between villages/tribes and different ethnic aboriginal residences. The mode of transmission of shigellosis in the township was likely via person-to-person within the 
communities. Since no shigellosis cases in Zhuoxi were reported from March 2, 2007 to December 31, 2010, suggesting that successful public health intervention has well controlled the endemic disease.

\section{Competing interests}

The authors declare that they have no competing interests.

\section{Authors' contributions}

CFK carried out the analysis as well as wrote and revised this manuscript. YSL designed and conducted this study as well as revised this manuscript. NTL, CSC, LYW and CYY participated in the study and interpreted the study findings. MCL performed the experiments. All authors have read and approved the final manuscript.

\section{Acknowledgments}

This study was supported by research grant DOH95-DC-2034 from the Taiwan Centers for Disease Control (Taiwan CDC). The authors thank the staff of the Hualien County Health Bureau for their assistance in the epidemiological investigation. The authors also thank Dr. Yi-Hsiung Tseng for helpful discussions and Mr. Min-Cheng Lin for help with administrative support.

\section{Author details}

'Institute of Medical Sciences, Tzu Chi University, No. 701, Zhongyang Rd., Sec. 3, Hualien 97004, Taiwan. ${ }^{2}$ The Third Branch Office, Centers for Disease Control, No. 20, Wenxin S. 3rd Rd., Taichung 40855, Taiwan. ${ }^{3}$ Master Program, Microbiology, Immunology, and Biochemistry, School of Medicine, Tzu Chi University, No. 701, Zhongyang Rd., Sec. 3, Hualien 97004, Taiwan. ${ }^{4}$ The Central Region Laboratory, Centers for Research, and Diagnostics, Centers for Disease Control, No. 20, Wenxin S. 3rd Rd., Taichung 40855, Taiwan. ${ }^{5}$ Department of Medicine, Mackay Medical College, No. 46, Sec. 3, Zhongzheng Rd., Sanzhi Dist., New Taipei City 25245, Taiwan. ${ }^{6}$ The Sixth Branch Office, Centers for Disease Control, No. 202, Sinsing Rd, Hualien 97058, Taiwan. IInstitute of Molecular Biology, National Chung Hsing University, No. 250, Kuo Kuang Rd., Taichung 40227, Taiwan. ${ }^{8}$ Department of Public Health, Tzu Chi University, No. 701, Zhongyang Rd., Sec. 3, Hualien 97004, Taiwan. The Fourth Branch Office, Centers for Disease Control, No. 752, Sec. 2, Datong Rd., Tainan 70256, Taiwan.

Received: 20 January 2013 Accepted: 26 July 2013

Published: 30 July 2013

\section{References}

1. Kotloff KL, Winickoff JP, Ivanoff B, Clemens JD, Swerdlow DL, Sansonetti PJ, Adak GK, Levine MM: Global burden of Shigella infections: implications for vaccine development and implementation of control strategies. Bull World Health Organ 1999, 77:651-666.

2. Wang SM, Ma JC, Hao ZY, Zhang ZY, Mason C, Sethabutr O, Von Seidlein L, Wang $X Y, X u Z Y$ : Surveillance of shigellosis by real-time PCR suggests underestimation of shigellosis prevalence by culture-based methods in a population of rural China. J Infect 2010, 61:471-475.

3. Chompook P, Samosornsuk S, Von Seidlein L, Jitsanguansuk S, Sirima N, Sudjai S, Mangijt P, Kim DR, Wheeler JG, Todd J, Lee H, Ali M, Clemens J, Tapchaisri P, Chaicumpa W: Estimating the burden of shigellosis in Thailand: 36-month population-based surveillance study. Bull World Health Organ 2005, 83:739-746.

4. Ram PK, Crump JA, Gupta SK, Miller MA, Mintz ED: Part II. Analysis of data gaps pertaining to Shigella infections in low and medium human development index countries, 1984-2005. Epidemiol Infect 2008, 136:577-603.

5. Chen JH, Chiou CS, Chen PC, Liao TL, Li JM, Hsu WB: Molecular epidemiology of Shigella in a Taiwan township during 1996 to 2000. J Clin Microbiol 2003, 41:3078-3088.

6. Chiou CS, Hsu WB, Wei HL, Chen JH: Molecular epidemiology of a Shigella flexneri outbreak in a mountainous township in Taiwan, Republic of China. J Clin Microbiol 2001, 39:1048-1056.

7. Lee YS, Liu MC, Ko CF, Lu CH, Tseng YH: Molecular epidemiology of Shigella flexneri in a long-stay psychiatric nursing center during 2001 to 2003. J Clin Microbiol 2005, 43:1353-1360.

8. Martin DL, Gustafson TL, Pelosi JW, Suarez L, Pierce GV: Contaminated produce-a common source for two outbreaks of Shigella gastroenteritis. Am J Epidemiol 1986, 124:299-305.
9. Reller ME, Nelson JM, Mølbak K, Ackman DM, Schoonmaker-Bopp DJ, Root TP, Mintz ED: A large, multiple-restaurant outbreak of infection with Shigella flexneri serotype 2a traced to tomatoes. Clin Infect Dis 2006, 42:163-169.

10. Swaddiwudhipong W, Karintraratana S, Kavinum S: A common-source outbreak of shigellosis involving a piped public water supply in northern Thai communities. J Trop Med Hyg 1995, 98:145-150.

11. Castell MJ, Gutiérrez AG, Rodolfo SR, Santos AA: Shigellosis outbreak with 146 cases related to a fair. Gac Sanit 2008, 22:35-39.

12. Saha T, Murhekar M, Hutin YJ, Ramamurthy T: An urban, water-borne outbreak of diarrhoea and shigellosis in a district town in eastern India. Natl Med J India 2009, 22:237-239.

13. Gutiérrez Gl, Naranjo M, Forier A, Hendriks R, DE Schrijver K, Bertrand S, Dierick K, Robesyn E, Quoilin S: Shigellosis outbreak linked to canteenfood consumption in a public institution: a matched case-control study. Epidemiol Infect 2011, 139:1956-1964.

14. Ko CF, Wang LY, Lin NT, Chiou CS, Yeh HC, Renn JH, Lee YS: Transmission and strain variation of Shigella flexneri 4 a after mass prophylaxis in a long-stay psychiatric centre. Epidemiol Infect 2013, 141:242-250.

15. Arvelo W, Hinkle CJ, Nguyen TA, Weiser T, Steinmuller N, Khan F, Gladbach S, Parsons M, Jennings D, Zhu BP, Mintz E, Bowen A: Transmission risk factors and treatment of pediatric shigellosis during a large daycare center-associated outbreak of multidrug resistant Shigella sonnei: implications for the management of shigellosis outbreaks among children. Pediatr Infect Dis J 2009, 28:976-980.

16. Garrett V, Bornschlegel K, Lange D, Reddy V, Kornstein L, Kornblum J, Agasan A, Hoekstra M, Layton M, Sobel J: A recurring outbreak of Shigella sonnei among traditionally observant Jewish children in New York City: the risks of daycare and household transmission. Epidemiol Infect 2006, 134:1231-1236

17. Boveé L, Whelan J, Sonder GJ, Van Dam AP, Van den Hoek A: Risk factors for secondary transmission of Shigella infection within households: implications for current prevention policy. BMC Infect Dis 2012, 12:347.

18. Shane AL, Tucker NA, Crump JA, Mintz ED, Painter JA: Sharing Shigella: risk factors for a multicommunity outbreak of shigellosis. Arch Pediatr Adolesc Med 2003, 157:601-603.

19. Mohle-Boetani JC, Stapleton M, Finger R, Bean NH, Poundstone J, Blake PA Griffin PM: Communitywide shigellosis: control of an outbreak and risk factors in child day-care centers. Am J Public Health 1995, 85:812-816.

20. Ahmed K, Shakoori FR, Shakoori AR: Aetiology of shigellosis in northern Pakistan. J Health Popul Nutr 2003, 21:32-39.

21. Centers for Disease Control and Prevention: Shigella surveillance: annual summary. Atlanta, Atlanta, Georgia: US Department of Health and Human Services; 2008

22. Shiferaw B, Shallow S, Marcus R, Segler S, Soderlund D, Hardnett FP, Van Gilder T: Trends in population-based active surveillance for shigellosis and demographic variability in FoodNet sites, 1996-1999. Clin Infect Dis 2004, 38(Suppl 3):S175-180.

23. Kuo CY, Su LH, Perera J, Carlos C, Tan BH, Kumarasinghe G, So T, Van PH, Chongthaleong A, Song JH, Chiu CH: Antimicrobial susceptibility of Shigella isolates in eight Asian countries, 2001-2004. J Microbiol Immunol Infect 2008, 41:107-111.

24. Taiwan Centers for Disease Control: Statistics of communicable diseases and surveillance report. Taipei: Taiwan Centers for Disease Control; 2011. in Chinese.

25. Yu TH, Lai MH, Wu PF, Lin T: An achievement report on the years 2000-4 bacillary dysentery prevention and control program for mountainous rural areas of Taiwan. Epidemiol Bull, Taiwan 2005, 21:277-313.

26. Wei HL, Wang YW, Li CC, Tung SK, Chiou CS: Epidemiology and evolution of genotype and antimicrobial resistance of an imported Shigella sonnei clone circulating in central Taiwan. Diagn Microbiol Infect Dis 2007, 58:469-475.

27. Chuang YY, Huang YC, Lin SY: Outbreak of Shigella sonnei gastroenteritis in Northeastern Taiwan. Pediatr Infect Dis J 2006, 25:92-94.

28. Ribot EM, Fair MA, Gautom R, Cameron DN, Hunter SB, Swaminathan B, Barrett TJ: Standardization of pulsed-field gel electrophoresis protocols for the subtyping of Escherichia coli 0157:H7, Salmonella, and Shigella for PulseNet. Foodborne Pathog Dis 2006, 3:59-67.

29. Tenover FC, Arbeit RD, Goering RV, Mickelsen PA, Murray BE, Persing DH, Swaminathan B: Interpreting chromosomal DNA restriction patterns produced by pulsed-field gel electrophoresis: criteria for bacterial strain typing. J Clin Microbiol 1995, 33:2233-2239. 
30. Clinical and Laboratory Standards Institute: Methods for dilution antimicrobial susceptibility tests for bacteria that grow aerobically; approved standard M07A8. 8th edition. Wayne, Pennsylvannia: Clinical and Laboratory Standards Institute; 2009.

31. Lee TM, Chang CY, Chang LL, Chen WM, Wang TK, Chang SF: One predominant type of genetically closely related Shigella sonnei prevalent in four sequential outbreaks in school children. Diagn Microbiol Infect Dis 2003, 45:173-181.

doi:10.1186/1471-2334-13-354

Cite this article as: Ko et al: Infrequent cross-transmission of Shigella

flexneri 2a strains among villages of a mountainous township in Taiwan with endemic shigellosis. BMC Infectious Diseases 2013 13:354.

\section{Submit your next manuscript to BioMed Central and take full advantage of:}

- Convenient online submission

- Thorough peer review

- No space constraints or color figure charges

- Immediate publication on acceptance

- Inclusion in PubMed, CAS, Scopus and Google Scholar

- Research which is freely available for redistribution 